\title{
Aprendizagem histórica: narrativas autobiográficas como dispositivos de formação
}

\section{Historical learning: autobiographical narratives as formation devices}

\author{
Jorge Luiz da Cunha ${ }^{1}$
}

\begin{abstract}
RESUMO
Narrar a própria experiência provoca estranhamentos do saber sobre o lugar comum e pode possibilitar conscientizações, nas relações entre história, estrutura social e trajetórias individuais. Nesse sentido, indagamos como a imaginação e a consciência histórica, o estranhamento e a desnaturalização, tidos como objetivos do ensino de história, se aproximam das narrativas autobiográficas como dispositivos de formação, estabelecendo um diálogo entre o ensino de história e o campo da pesquisa (auto)biográfica em educação. Este trabalho põe em diálogo as orientações legais sobre as especificidades da aprendizagem histórica e as narrativas autobiográficas como dispositivos de formação. Discute, também, a fundamentação epistemológica do trabalho com narrativas autorreferenciais nas aulas de história; e, por fim, apresenta e analisa a aplicação de uma proposta de ensino de história a partir de narrativas autobiográficas de alunos do Ensino Médio. A análise dos relatos, decorrentes da proposta, foi realizada com base na análise textual discursiva, cujas unidades de análise também foram fundamentadas no conceito de construção e reconstrução da aprendizagem, nas relações entre a reflexão autobiográfica e a imaginação histórica e no papel da aprendizagem histórica na constituição de uma consciência histórica. Estranhar e desnaturalizar o que se sabe sobre si, o que se escuta sobre si e deixar em suspensão para novas reorganizações, para construções e reconstruções da aprendizagem e, principalmente, para uma prática de questionamentos em que a interrogação não versa somente sobre o outro, mas sobre si na relação com outros e com os fatos históricos, eis aí talvez uma tarefa da educação em que a história adquire importância
\end{abstract}

DOI: $10.1590 / 0104-4060.46025$

1 Universidade Federal de Santa Maria. Santa Maria, Rio Grande do Sul, Brasil. Av. Roraima, nº 1000. Bairro: Camobi. CEP: 97105-900.E-mail: Jlcunha11@yahoo.com.br 
na formação dos jovens. Desse modo, o que sustentamos é a centralidade da relação sociedade-indivíduo no ensino de história na educação escolar.

Palavras-chave: aprendizagem histórica; narrativas autobiográficas; educação histórica; dispositivos de formação; estranhamento e desnaturalização.

\begin{abstract}
Narrating our own experience provokes estrangements of knowledge about the common place and they can enable awareness of the relations between history, social structure and individual trajectories. In this regard, we inquire how imagination and historical consciousness, estrangement and denaturalization, considered the objectives of history teaching, approach autobiographical narratives as formation devices, establishing a dialogue between history teaching and the (auto)biographical research field in education. This work puts in discussion the legal orientations about the particularities of history learning and the autobiographical narratives as formation devices. It also debates the epistemological foundation of the work with self-referential narratives in history classes; and finally, it presents and analyses the application of a history teaching proposal starting from the autobiographical narratives of high school students. The analysis of the accounts, resulted from the proposal, was carried on the basis of discursive text analysis, whose analytical units were also founded in the concept of learning construction and reconstruction, in the relations between autobiographical reflection and historical imagination and in the role of history learning in the formation of a historical consciousness. Finding strange and denaturalizing what is known about yourself, what is heard about yourself and letting it suspended for new reorganizations, for learning construction and reconstruction and, mainly, for a questioning technique in which interrogation doesn't refer only to the other, but to you in relation to others and to historical facts. This may be an educational task in which history gains importance in the youths' formation. Thus, what we support is the centrality of the society-individuals relation in history teaching in school education.
\end{abstract}

Keywords: historical learning; autobiographical narratives; history education; formation devices; estrangement and denaturalization.

\title{
Introdução
}

Esta reflexão sobre o ensino de história e a aprendizagem histórica fundamenta-se nos resultados de uma experiência escolar com alunos do En- 
sino Médio em aulas de história. Esta experiência foi inspirada num trabalho anterior, realizado em 2014, também em turmas do Ensino Médio, em aulas de sociologia (RÖWER; CUNHA; PASSEGGI, 2015, p. 17-45), como parte das atividades de pesquisa do Núcleo de Estudos sobre Educação e Memória (CLIO) e do desenvolvimento de um projeto de doutorado junto ao Programa de Pós-Graduação em Educação, da Universidade Federal de Santa Maria, Rio Grande do Sul. (RÖWER, 2016).

A experiência empírica de utilização de narrativas autobiográficas em aulas de história junto a alunos do Ensino Médio, que contou com a colaboração de professores de história, foi realizada em três escolas públicas, no município de Santa Maria, Rio Grande do Sul, durante o primeiro semestre do ano de 2015.

A principal justificativa para a realização destas duas experiências que buscam aproximar dialogicamente o exercício de (re)memorações e narrativas autobiográficas com o ensino de sociologia, a partir de 2014, e de história, a partir de 2015, encontra-se já nas discussões estimuladas pela Constituição Federal de 1946. A primeira constituição que estabelece garantias efetivamente democráticas como a igualdade de todos diante da lei; especialmente, a liberdade de consciência, de pensamento, de expressão, de organização e de manifestação; o respeito ao espaço privado e pessoal; garantias legais de inviolabilidade dos direitos fundamentais da cidadania (BRASIL, 1946, Tit. IV, Cap. II, Art. 141), entre outros a educação: “A educação é direito de todos e será dada no lar e na escola. Deve inspirar-se nos princípios de liberdade e nos ideais de solidariedade humana". (BRASIL, 1946, Tit. IV, Cap. II, Art. 166).

Este contexto democrático, proporcionado pela Constituição de 1946, estimulou vários pensadores da educação à reflexão, à pesquisa e à defesa de princípios pelos quais se continua a lutar no tempo presente, em nosso país. O principal deles foi Anísio Teixeira, que se engajou em uma árdua batalha em defesa e divulgação da profissionalização da educação e de sua efetividade, para além da eficácia proposta pela legislação:

Muitos dos equívocos e confusões do país, em matéria de educação, os quais tornam obscura qualquer discussão, provém do erro de querer resolver, pela lei, o que deve ser deixado para o controle delicado e progressivo dessa opinião especializada e profissional. Quando isto for devidamente reconhecido, teremos criado as condições para o progresso contínuo e crescente das nossas instituições educacionais, dotadas que serão elas da autonomia necessária para sua própria direção. Esta autonomia profissional, que nos cumpre reivindicar, para todos os aspectos especializados do processo educativo, é uma condição essencial para a liberdade, como 
é concebida no Estado moderno e democrático. Se isso conseguirmos, tudo mais será conseguido. (TEIXEIRA, 1956, p. 20).

Esta postura envolve um conceito de liberdade e de vontade próprias que recuperam as justificadamente humanas razões da educação, pois fundamenta a autonomia não como algo presenteado por alguma autoridade ou pelos deuses, mas construído na medida em que é exercitado.

Esta autonomia leva à necessidade da ação, como ação política em detrimento de uma disposição humana meramente especulativa que, invariavelmente, conduz a destinação da condição humana a espaços ideais e transcendentes. Esta disposição política e crítica é condição para elevar-se do sensível ao inteligível, não apenas conhecendo as condições objetivas da existência de si (de seu corpo e de todas as relações possíveis como a materialidade dos contextos de sua existência), mas significando tudo através do conhecimento da humana existência.

Ainda que o Golpe Civil-Militar de 1964 e a Constituição de 1967 tenham suprimido estes princípios, eles foram recuperados na Constituição de 1988 e sua atualidade ainda se faz presente diante da crise política e econômica que vivenciamos no presente e que produz efeitos também sobre os conceitos e as práticas educativas nas escolas e fora delas.

$\mathrm{O}$ trabalho que aqui se apresenta insere-se neste contexto sociopolítico e no campo da educação através da pesquisa autobiográfica em educação.

\section{O ensino de história, a aprendizagem histórica e o uso das narrativas autobiográficas como dispositivo de formação}

O exercício de (re)memoração autobiográfica é desencadeador de um processo de produção de consciência de si. Escrever sua história de vida é, portanto, o dispositivo que, ao ser acionado, permite a construção de uma representação de si que, quando associado ao conhecimento e à reflexão dos conteúdos das disciplinas escolares - neste caso os conteúdos pertinentes ao ensino de história no Ensino Médio -, possibilita deslocamentos de representação praticada para um estágio de representação refletida. (PINEAU; LE GRAND, 2012; PINEAU, 1980).

Lembrar-se de si, (re)memorar seu passado, refletir sobre si como resultado de um processo complexo de influências e escolhas, narrar e escrever sobre si, 
é um exercício que se apresenta como um princípio organizador que resulta em uma representação que o sujeito faz de si.

Contudo, permanecer neste estágio conduz inevitavelmente à fixação do sujeito em uma estrutura existencial que dificulta o fluxo da processualidade como resultado consequente de um exercício de enunciação narrativa de percursos existenciais. (PEREIRA, 2010, p. 129). Situação que nos aproxima da crítica de Rüsen $(2013,2015)$ aos resultados "tradicionais" do historicismo quando transportados acriticamente aos espaços do ensino de história. Uma narrativa sobre o passado justificada pela historiografia, que explica as configurações do humano no presente e que acaba por resultar numa concepção posta, definitiva e ideologizada da história e do presente humanos - no que diz respeito às práticas docentes (sempre bem intencionadas!) -, resulta num processo de colonização das consciências dos jovens alunos do Ensino Médio!

Para justificar e esclarecer a base metodológica desta experiência de ensino de história busca-se a relação entre conhecimento, sentido e construção de si (JOSSO, 2010); a reflexividade autobiográfica (PASSEGGI, 2011), que implica em autonomia cognitiva e na consciência de si, representações dinâmicas de compreensão de si em contextos particulares e amplos - da cultura e identidade pessoal e grupal à inserção em processos históricos globais; e, a relação entre biografia e aprendizagem (DELORY-MOMBERGER, 2006, 2012a, 2012b), que está na centralidade da contribuição epistemológica do campo da pesquisa autobiográfica em educação e na construção de uma proposta didática para o ensino de história. (RÖWER; CUNHA; PASSEGGI, 2015).

Ressalte-se - considerando que é o campo de práticas e pesquisas autobiográficas que fundamenta a experiência aqui relatada - a necessária diferenciação terminológica e conceitual entre biografia, que se refere à escrita de vida do outro (PINEAU, 1999); autobiografia, como escrita de si, da própria vida; relatos de vida, que dizem respeito às configurações de uma trajetória de vida; e, história de vida, concebida como uma denominação genérica em formação e investigação que congrega uma variabilidade de pesquisas e de projetos envolvidos na construção de sentidos baseados nas trajetórias individuais (RÖWER; CUNHA; PASSEGGI, 2015, p. 27), que envolve um processo de expressão da experiência. (PINEAU, 2012). Além disso, é necessário especificar o conceito de fato biográfico e o conceito de biografização, que decorrem das leituras de Delory-Momberger (2014):

O fato biográfico se inscreve em nós, em nosso interior, em nossas percepções do vivido, ainda não compreendido e significado, ainda não narrado e explicitado em uma sequência que proporciona encadeamento 
e sentido. O fato biográfico se refere aos silêncios do vivido que constituem as memórias. $\mathrm{O}$ fato biográfico se refere aquela imagem do eu experenciado, mas ainda não compreendido entre a singularidade e a socialização, entre o eu e aquilo que me aconteceu. (RÖWER; CUNHA; PASSEGGI, 2015, p. 28).

A biografização necessita e precede o fato biográfico que "[...] consiste na ação de escrever (grafar) a narrativa de sua própria história de vida (autobiografia) e ou a história de vida de outrem (biografia)". (PASSEGGI, 2011, p. 15).

A relação entre autobiografia e aprendizagem (DELORY-MOMBERGER, 2006, 2012a, 2012b, 2014) pode ser legitimada a partir das seguintes afirmações: 1 - os saberes subjetivos e não formalizados influenciam no modo como as pessoas investem e transitam nos espaços de aprendizagens formais e que tornar-se cônscio destes saberes, torna possível ressignificar sentidos e projetos de vida em formação (DELORY-MOMBERGER, 2006); 2 - a compreensão dos significados das experiências de formação e aprendizagem de jovens e adultos em suas construções biográficas e autobiográficas individuais, nas suas relações com os outros e com o mundo social, torna-se constituidor (DELORY-MOMBERGER, 2012a); e, 3 - a aprendizagem de saberes escolares estabelece uma relação de complementaridade e reciprocidade com as aprendizagens e saberes biográficos, permitindo revisitações de si e outras projeções, ou ainda "biografar-se de outro modo". (DELORY-MOMBERGER, 2014, p. 136).

Para nutrir e sustentar a relação aqui defendida entre o ensino de história e o campo da pesquisa autobiográfica em educação como dispositivo de formação, reafirma-se a intencionalidade desta experiência e das práticas escolares delas decorrentes em produzir estranhamentos e desnaturalizações como princípios metodológicos gerais e objetivos de uma educação ancorada no conhecimento e na produção processual de consciência de si e dos contextos sociais de inserção, dos mais particulares aos mais globais, do sujeito à humanidade. Isto é, objetivar a história ensinada na compreensão de si e do outro. Possibilidade de compreender e compreender-se de outro modo, superando aquele que resulta de um ensino de história que se identifica como resultado de uma prática docente ideologicamente proselitista. A possibilidade de "biografar-se de outro modo" (DELORY-MOMBERGER, 2014) resulta na possibilidade de protagonizar novas compreensões de si, do outro e do mundo.

Pode-se associar Ferrarotti (2014) à crítica das práticas ideologicamente proselitistas do ensino de história, que ainda caracterizam em grande medida nossa educação básica no Brasil. Para ele, 
A história de vida como método autônomo implica necessariamente uma historicidade não historicista. Em outras palavras, implica uma ruptura com a concepção da história enquanto sucessão diacrônica, orientada para a suposta verdade de um sentido geral, monopolizado pelas elites, depositárias exclusivas do valor. (FERRAROTTI, 2014, p. 50-51).

Este autor vai ainda mais longe, ao afirmar que esta é uma concepção empobrecida da realidade social, "ossificada", que, privada de suas tensões e dinâmicas internas, apresenta a história apenas como a história das elites,

Da mesma maneira, esse empobrecimento refletiria uma concepção da metodologia como conjunto de técnicas específicas, mecanicamente intercambiáveis, instrumentalidade pura a ser aplicada ao mundo humano. Nessas condições de instrumentalização [...] a única história possível não é a história de vida de cada um, mas, antes, a história historicista. Talvez não seja um fato casual constatar que os historiadores, idealistas ou marxistas, aceitariam de bom grado as ciências sociais, contanto que elas se limitassem a um papel auxiliar, como instrumentos da atividade intelectual privados de um verdadeiro valor cognitivo plenamente conceitual, isto é, privados de autonomia. (FERRAROTTI, 2014, p. 50).

A ciência histórica que deve contrapor-se a esta "história historicista", e às práticas docentes na educação básica por ela contaminadas, fundamenta-se: 1 - em uma práxis metodicamente estruturada na experiência do historiador e dos destinatários de suas narrativas sobre os fatos humanos registrados na memória oral, documental ou monumental (RÜSEN, 2010, p. 100-108), "O pensamento histórico faz-se científico ao se submeter, por princípio, à regra de tornar o conteúdo empírico das histórias controlável, ampliável e garantível pela experiência" (RÜSEN, 2010, p. 101); 2 - em uma relação com as normas ou referenciais plausíveis e aceitáveis quanto à vinculação dos fatos humanos acontecidos no tempo passado com o presente, isto é, referencial que legitima as práticas de pesquisa e as formulações do historiador (RÜSEN, 2010, p. 108-118); 3 - na metodização da relação com as ideias a partir da prática narrativa histórica (que não se confunde ou coincide com a narrativa literária), pois ao historiador cabe organizar suas ideias - alicerçadas em suas práticas científicas -, de forma a atribuir sentido a suas teses e oferecer aos destinatários de seu trabalho condições para também atribuir sentido à sua existência individual e coletiva, a partir dos princípios da 
superação do passado, como história, no presente. (BAUMGARTNER, 1979, p. 259-289; RÜSEN, 2010, p. 118-126).

O que devemos procurar através da educação, e nela a história desempenha um papel humanizador e político fundamental, são o equilíbrio e a prudência:

[...] evitando sempre os extremos. Por isto devemos ser contra o revolucionário que "já não preserva recordações de seu bisavô, mas compromete-se a escrever uma detalhada e autoritativa biografia de seu bisneto" (CHESTERTON, 2013, 402), que nutre aquele desejo de nascer sem cordão umbilical afirmando de maneira disforme ser um adulto de apenas um dia de vida; da mesma forma devemos negar os apetites do reacionário, aquele que sempre está tentando levar a sociedade para uma época idealizada do passado que ele jura ser a era da perfeição. Aquele ser que acorda e faz seus planos para o ontem, dizendo confiante para seus amigos que segunda passada ele irá começar seu regime. Resta-nos, então, buscar no passado os bons exemplos que darão consistência para seguirmos rumo a um futuro sensato. (ALVES, 2016, não paginado).

Permanecer humano sempre e acima de tudo só é possível através da preservação da dimensão de humanidade, dada implicitamente com as pretensões de racionalidade do conhecimento histórico (RÜSEN, 2015, p. 270), significado e ressignificado na relação com o sujeito, a sua memória e a sua história.

\section{Narrativas autobiográficas em aulas de história do Ensino Médio}

A experiência empírica de utilização de narrativas autobiográficas em aulas de história, junto a alunos da primeira série do Ensino Médio, foi realizada em três escolas públicas, no município de Santa Maria, Rio Grande do Sul. A proposta foi apresentada, discutida e planejada com os professores de história dos primeiros anos do Ensino Médio. Foram envolvidas na atividade três turmas, totalizando 97 alunos, que participaram ativamente da proposta, desenvolvida entre os meses de março e junho, primeiro semestre do ano letivo de 2015. Todas as atividades dos professores colaboradores e dos membros do grupo de pesquisa envolvido foram registradas em diários de campo que apresentam as reflexões da prática proposta de ensino de história que se deseja pesquisar. 
Também foram lembradas e discutidas as políticas educacionais que autorizam e legitimam a experiência com narrativas autobiográficas em aulas de história do Ensino Médio (BRASIL, 1999; BRASIL, 2002; BRASIL, 2006) e, inclusive, a sua condução metodológica:

Para o saber histórico escolar, os três eixos fundamentais formados a partir dos conjuntos de competências de ler, escrever e resolver problemas deverão ser tomadas como propostas norteadoras da elaboração do conhecimento. (MACEDO, 2009, p. 53).

O fio condutor para a realização desta proposta de ensino a partir da abordagem autobiográfica como dispositivo de formação é formado pelas fases descritas por Josso (2010) sobre a abordagem biográfica como metodologia da pesquisa-formação:

A originalidade da metodologia de pesquisa-formação em histórias de vida diz respeito, em primeiro lugar, à nossa constante preocupação com que os autores de narrativas consigam produzir conhecimentos que tenham sentido para eles e que eles próprios se inscrevam num projeto de conhecimento que os institua como sujeitos. (JOSSO, 2010, p. 33).

A construção da metodologia de intervenção nas aulas de história no Ensino Médio, associando história e autobiografias individuais como dispositivo de formação, ocorreu em etapas:

a) sensibilização do grupo de alunos em relação às escritas de si através da mediação do coordenador do projeto e do docente da classe;

b) elaboração de escritas narrativas autobiográficas individuais, estruturadas a partir de (re)memorações de experiências de vida;

c) interpretação das narrativas autobiográficas produzidas através da leitura, interpretação e discussão em grupos de três alunos;

d) desenvolvimento dos conteúdos previstos para o primeiro semestre do ano letivo: a) a tecnologia e a invenção nas sociedades antigas e medievais, b) o nascimento das fábricas e do maquinário, c) o impacto social da industrialização nas sociedades contemporâneas; ancorados nos conceitos estruturantes trabalho, cultura, representação; e, tendo como objetivos o desenvolvimento de competências e habilidades: a) comparar o papel das invenções, técnicas e 
tecnologias em diferentes épocas, b) analisar documentos e bibliografia e extrair informações e conceitos, c) compreender as distinções entre sistemas de organização de trabalho, vinculando-os ao momento histórico em que foram criados, d) interpretar as representações do mundo do trabalho nas imagens artísticas (cinema, fotografia, pintura) do século 20 (MACEDO, 2009, p. 64);

e) releitura dos relatos autobiográficos escritos no início do semestre e sua reinterpretação na relação com os conteúdos trabalhados nas aulas de história do semestre;

f) reescrita das narrativas autobiográficas e das possíveis novas interpretações e aprendizados;

g) nas duas últimas semanas do semestre letivo, em grande grupo, foram realizados seminários com a finalidade de conhecer e compreender as percepções sobre a experiência realizada e, principalmente, avaliar a relação entre as trajetórias individuais escritas e narradas e os conteúdos desenvolvidos nas aulas de história.

A análise, o estabelecimento de relações entre as categorias e a interpretação geraram compreensões que versam sobre: - a desnaturalização como condição da construção e reconstrução da experiência, identificadas pela literalidade das explicações, dos conceitos ou pela sua substancialidade; - o estranhamento de si pela reflexividade na escrita e estranhamento do outro pela leitura dos relatos de outros e pela dinâmica de suas narrativas; - a estranheza ao perceber a diferença, a igualdade e a possibilidade de ser diferente; - a importância de um tema que conduza à reflexão; - as reflexões sobre o preconceito como decorrência do estranhamento e da desnaturalização; - a consciência de si como um sujeito que se constitui em meio às influências (conhecimento/reconhecimento) revelou-se como um elemento de disposição para a aprendizagem, para a reconstrução da experiência; - a percepção da influência familiar corrobora esta interpretação; e, - a percepção de autoconstrução de si individualizada e individualizante resultou em parte em uma não disposição e em parte em uma abertura para outras reflexões e possibilidades de outras percepções de si e do outro. (RÖWER; CUNHA; PASSEGGI, 2015, p. 17-45; RÖWER, 2016).

\section{Considerações finais}

O objetivo principal da experiência com o ensino aqui apresentada foi estudar, experienciar e registrar compreensões dos sentidos do ensino de história 
e as possibilidades potenciais das escritas de si como dispositivo de formação no âmbito escolar, de um modo geral e, no Ensino Médio, de um modo particular.

A utilização de dispositivos de auto e heterobiografia nas aulas de história fomenta estranhamentos de si e do outro e desnaturalizações, colaborando para a quebra de preconceitos e para a construção de uma educação autônoma, auto e socialmente referenciada, que se constitui como resistência à cooptação e à submissão ao proselitismo ideológico.

Esta concepção de história, de ensino de história e de aprendizagem histórica, se perfila a um projeto humanista histórico cuja importância política é crescente diante dos acontecimentos e problemas contemporâneos locais e globais:

Fique claro, desde o início, ser necessário preservar a dimensão de "humanidade", dada implicitamente com as pretensões de racionalidade do conhecimento histórico. A centralidade da relação a si próprio, formadora da identidade, deve incluir sua qualidade humana, partilhada com todos os outros. Com isso se teria, em termos identitários pragmáticos, a confirmação ou ratificação da concepção de uma evolução cultural da humanidade. A categoria da igualdade, inserida na universalização da qualidade do ser humano, confisca ao etnocentrismo a arma que emprega para rebaixar os outros a um patamar inferior na humanidade. (RÜSEN, 2015, p. 270; RÜSEN, 2013, p. 277-278).

O conhecimento histórico tem sua centralidade, desde a sua origem, na relação entre o sujeito humano e a sociedade:

Perceber e considerar a auto-observação e auto-reflexão como meio de estranhar para então questionar, avaliar e compreender as estruturas, os processos, os condicionantes sociais, para entender conceitos e temas, pode ser um procedimento significante, na medida em que faz o jovem compreender a sua própria trajetória e a relação sociedade-indivíduo. (RÖWER; CUNHA; PASSEGGI, 2015, p. 40).

A experiência de ensino de história com narrativas autobiográficas como dispositivo de formação, relatada neste texto, propiciou grande alcance, não somente de reflexões motivadas pelas possibilitadas de confrontação dos discursos reproduzidos pelas políticas públicas e pela historiografia tradicional - reproduzida nos livros didáticos e também (em grande medida) na formação 
dos professores de história - através da experiência vivida pelos sujeitos envolvidos, pesquisadores, professores e jovens alunos do Ensino Médio. A proposta apresentada configura-se, portanto, como uma possibilidade que busca contribuir para a compreensão do potencial das narrativas autorreferenciais para a qualificação das aulas de história enquanto potencial de produção de humanidades, autonomias e consciências.

\section{REFERÊNCIAS}

ALVES, P. H. Não existe ética num país sem ética. Obvious Newsletter, 2016. Disponível em: <http://obviousmag.org/do_contra/2016/02/nao-existe-etica-num-pais-sem-etica. $\mathrm{html}$ ?utm_source $=$ obvious + subscribers\&utm_campaign $=$ a14f3f464a-MAILCHIMP DAILY_EMAIL_CAMPAIGN\&utm_medium $=$ email\&utm_term $=0 \_7 \mathrm{~d} 1 \mathrm{f} 58 \mathrm{ded} 8$ a14f3f464a-213567869\&goal=0_7d1f58ded8-a14f3f464a-213567869>. Acesso em: 05 mar. 2016.

BAUMGARTNER, H. M. Erzählung und Theorie in der Geschichte. In: KOCKA, J. u.; NIPPERDEY, T. (Hrsg.). Theorie und Erzählung in der Geschichte. München: DTV, 1979.p. 259-289.

BRASIL. Constituição dos Estados Unidos do Brasil 1946. Rio de Janeiro: Imprensa Nacional, 1946.

BRASIL. Parâmetros curriculares nacionais para o Ensino Médio. Brasília: Ministério da Educação/Secretaria de Educação Média e Tecnologia, 1999.

BRASIL. PCN + Ensino Médio: orientações educacionais complementares aos parâmetros curriculares nacionais. Ciências humanas e suas tecnologias. Brasília: Ministério da Educação/Secretaria de Educação Média e Tecnológica, 2002.

BRASIL. Orientações curriculares para o Ensino Médio. Brasília: Secretaria de Educação Básica, 2006. Ciências humanas e suas tecnologias, v. 3.

DELORY-MOMBERGER, C. Formação e socialização: os ateliês biográficos de projeto. Educação e Pesquisa, v. 32, n. 2, p. 359-371, maio/ago. 2006.

DELORY-MOMBERGER, C. A condição biográfica. Ensaios sobre a narrativa de si na modernidade avançada. Natal: UFRN, 2012a.

DELORY-MOMBERGER, C. Abordagens metodológicas na pesquisa biográfica. Revista Brasileira de Educação, v. 17, n. 51, p. 523-535, set./dez. 2012 b.

DELORY-MOMBERGER, C. Biografia e educação: figuras do indivíduo-projeto. Natal: EDUFRN, 2014. 
FERRAROTTI, F. História e histórias de vida. O método biográfico nas ciências sociais. Natal: EDUFRN, 2014.

JOSSO, M.-C. Experiências de vida e formação. 2. ed. São Paulo: Paulus; Natal: EDUFNR, 2010.

MACEDO, J. R. História. Referencial curricular. In: RIO GRANDE DO SUL. Referencial curricular: lições do Rio Grande. Ciências Humanas e suas tecnologias. Porto Alegre: Secretaria de Estado da Educação, 2009. p. 49-67.

PASSEGGI, M. da C. A pesquisa (auto)biográfica em educação: princípios epistemológicos, eixos e direcionamentos da investigação científica. In: VASCONCELOS, M. de F.; ATEM, É. (Org.). Alteridade: o outro como problema. Fortaleza: Expressão Gráfica, 2011. p. 13-39.

PEREIRA, M. V. Sobre histórias de vida e autoformação: um enfoque ético e estético. In: ABRAHÃO, M. H. M. B. (Org.). (Auto)biografia e formação humana. Porto Alegre: EDIPUCRS, 2010. p. 123-138.

PINEAU, G. Vies des histories de vie. Montréal: Université de Montréal, 1980.

PINEAU, G. Experiências de aprendizagem e histórias de vida. In: CARRÉ, P.; CASPAR, P. Tratado das ciências e das técnicas de formação. Lisboa: Instituto Piaget, 1999.

PINEAU, G.; LE GRAND, J.-L. As histórias de vida. Natal: EDUFRN, 2012.

RÖWER, J. E. Por uma sociologia da suspensão: ensino de sociologia e narrativas como dispositivo de formação. 206 p. Tese (Doutorado em Educação) - Universidade Federal de Santa Maria, Santa Maria, 2016.

RÖWER, J. E.; CUNHA, J. L. da; PASSEGGI, M. da C. F. B. S. Por uma Sociologia da Suspensão: da recursividade entre concepções e práticas. Revista Em Tese, Florianópolis, v. 12, n. 2, p. 17-45, 2015.

RÜSEN, J. Razão histórica. Teoria da história: os fundamentos da ciência histórica. Brasília: UNB, 2010.

RÜSEN, J. Historik. Theorie der Geschichtswissenschaft. Köln/Weimar/Wien: Böhlau Verlag, 2013.

RÜSEN, J. Teoria da História. Uma teoria da história como ciência. Curitiba: Editora UFPR, 2015.

TEIXEIRA, A. S. A educação e a crise brasileira. São Paulo: Companhia Editora Nacional, 1956. Biblioteca Pedagógica Brasileira, v. 64.

Texto recebido em 23 de março de 2016.

Texto aprovado em 27 de março de 2016. 
